\title{
Exploring the Underlying Dimensions of Job Satisfaction in Quality Management Practices
}

\author{
Sisay Addis ${ }^{1 *} \quad$ Akshay Dvivedi $^{2} \quad$ Birhanu Beshah $^{3}$ \\ 1.School of Mechanical and Industrial Engineering, Institute of Technology, Debre Markos University, Debre \\ Markos, Ethiopia \\ 2.Department of Mechanical and Industrial Engineering, Indian Institute of Technology Roorkee, Roorkee- \\ 247667, Uttarakhand, India \\ 3.School of Mechanical and Industrial Engineering AAiT, AAU, Addis Ababa, Ethiopia
}

\begin{abstract}
Humans issues involved in quality management are an important determinant of operational performance as it is crucial for quality improvement. Accordingly, the relationships between quality management (QM) and job satisfaction (JS) have recently received an attention in the QM literature. However, the available researches tried to study such relationships by merely relating their respective factors, obtaining critically dispersed findings and contributing in fragmented knowhow about the issue. The main objective of the present study is to examine the mechanics of relationships between QM \& JS and create understandings on how one is constituted within the corpus of the other. A case study was carried out in the manufacturing organizations of Ethiopia. Data triangulation was used in the form of questionnaire survey and focus group interviews of shop floor workers. The study identified the underlying dimensions that are believed to realize JS. All of the dimensions were crosschecked with the fundamental ideas in the QM theory and shown to be constituted in it. It augments the existing understanding of the connection between QM and JS. Through the increased knowledge from this study, managers can maximize organizational gains via human resource perspectives.
\end{abstract}

Keywords: Quality management; job satisfaction; Ethiopia.

Keywords: Claims, Delivery, Administration

DOI: $10.7176 /$ IEL/9-2-03

Publication date:March $31^{\text {st }} 2019$

\section{Introduction}

People are considered as organizational asset that cannot be easily imitated by competitors (Wright et al., 1994). It is, therefore, imperative for organizations to build and preserve their human capacity more than ever before. Human resources and operations are intimately tied to each other in virtually all business scenarios (Yee et al., 2008). Humans are part of operations systems, both as system operators and decision-making managers (Neumann and Dul, 2010). The importance of employee attitudes such as job satisfaction (JS), and its impact on operational performance is of paramount to the success, and even the survival of organizations (Yee et al., 2008). Particularly, scholars argued that JS of employees is a crucial element for organizational success, which suggests that the workforce influences not only total quality but also total success of the organization (Jimenez and Martinez, 2009). JS makes workers to engage in organizational citizenship behaviors and contribute better inrole and extra-role performances (Ellickson and Logsdon, 2002; Addis et al., 2017b).

Organizations need to adopt modern management philosophies that helps in technical management of labor and then brings organizational wide change. One of the comprehensive management philosophies to attain these results is the realization of quality management $(\mathrm{QM})$. QM is a management philosophy that aims to harness HR in the most effective way to achieve objectives of an organization. Effective management results in greater commitment of employees to their organizations. The literature portrays a widespread consensus that the behavioral aspects in organizations drives the ultimate objectives of QM such as customer satisfaction (Ooi et al., 2013). Nevertheless, the wellbeing of employees is vaguely described in the area of QM, while it likely affects different aspects of employees at workplaces (Addis et al., 2019). In their review on the evolution of quality, Schroeder et al. (2005) recommended that human attributes involved in QM should be an increasing interest in operations management as it is crucial for quality improvement. The present study concerns the association between QM and JS of employees. Their relationships have already received an attention in the QM literature (D Menezes, 2012; Del Río-Rama et al., 2016). Previous researches tried to study such relationships by merely relating their respective factors and resulted in obtaining critically dispersed findings, contributing in fragmented knowhow about the issue. Some authors find positive relationship within manufacturing organizations (Prajogo and Cooper, 2010), while others reported no relationship within workplace employments (D Menezes, 2012; Lam, 1995). Thus, the facts concerning the linkage between QM and JS remain largely unclear. The present study is a continuation of the efforts that are being made in finding the appropriate relationship between JS and QM. Since this is one of the important area of study in the domain of QM, systematic researches are valuable to understand their sources of relationship (Liu and Liu, 2014). Scholars argued that while establishing a 
relationship between study variables, it is more useful to create an understanding of how one is constituted within the corpus of the other (Lagrosen et al., 2010). This is what the present study uniquely attempts to do. The main purpose of the present study is to examine the mechanics of the relationships between QM and JS to understand their sources of relationship. It will help in augmenting the existing understanding of the issue by creating an understanding of how the factors of the study variables are constituted to each other.

\section{Quality Management (QM)}

Successful implementation and execution of strategies are partly dependent on manager's ability to nurture a strategy-supportive work climate that can make people motivated. Managing best-known practices of QM are amongst strategy execution processes in organizations (D Menezes, 2012). QM comprises 'hard' and 'soft' practices (Wilkinson, 1992). The hard side associates a range of tools and techniques required for the improvement of production processes including seven quality tools, just-in-time inventory, quality function development, etc. On the other hand, the soft side is associated with people factors such as leadership, employee empowerment, teamwork, culture, etc. Many commentators argued that organizations should primarily understand the soft side (i.e. people-related factors) for variety of reasons in order to attain successful implementation of QM (Prajogo and Cooper, 2010). First, the soft factors create an environment where the 'hard' QM can be implemented by supporting and empowering employees to maximize their work potential (Rahman and Bullock, 2005). This explains that promoting and upgrading hard QM practices may not necessarily improve performance, because ultimately it is 'people that make quality happen' (Prajogo and Cooper, 2010). Second, in addition to the direct effects, soft QM has an indirect effect on organizational performance through its effect on hard QM (e.g. Rahman and Bullock, 2005). Third, in their study on exploring the relationships between "soft" and "hard" QM elements, Psomas and Fotopoulos (2009) reported that quality improvement and consolidation of company's market position are mainly influenced by initially adopting "soft" practices followed by 'hard' QM practices.

In literature, multiple people-related QM practices are recommended that are believed to influence satisfaction of employees at workplaces (e.g. Guimaraes, 1996; Psomas and Fotopoulos, 2009). This research considered a set of factors containing 'top management leadership commitment (TMLC)', everybody's participation (EP) and continuous improvement (CI) practices. Although not exhaustive, these practices have often been considered the critical factors of QM in different studies. Dahlgaard et al. (2002) regarded them the principles of QM and considered as pillars for the implementation of QM. They are also recognized as part of the 'QM wheel in an organization' that are crucial for product quality (Sarathy, 2013). In an empirical research, Lagrosen et al. (2010) found them having high correlation with workplace attitude of employees in organizations. Further, Lagrosen et al. (2010) enumerates the three practices as vital humanistic core values relevant to organizational excellence from a QM's perspective.

\section{Job Satisfaction (JS)}

Human capital is the greatest asset that an organization can possess (Abdulla et al., 2011). To be successful, it requires collective action from every member of the organization (Ooi et al., 2013). Employees take interest on organizations based on the degree to which the organization values their welfare, security and comfort (Mabasa and Ngirande, 2015). JS is considered as a mental, physiological, and environmental situation, which stimulates a person to express satisfaction with their occupation (Saleem, 2015). It is a pleasant feeling that people acquire when their expectations from the job have been met (Weiss, 2002). JS is greatly liked with organizational performances and considered as one of the most important factors that enable organizations achieve competitive advantages over their competitors (Karia and Asaari, 2006). Also, lack of JS results in work-related fatigue and affects organizations from a holistic 360-degree point of view (Addis et al., 2017b). Hence, organizations should understand how employees can be kept satisfied, in searching for greater organizational performance (Addis et al., 2018). Effective management of people results in greater commitment of employees to their organizations.

\section{The case study}

Leather and leather products are amongst the most widely traded commodity and plays a remarkable role in world's economy (contributes approximately US\$100 billion/year) (UNIDO, 2010). According to the report made by United Nations, $78.3 \%$ of raw materials (hides and skins) for leather processing industries in the world are produced in developing countries, with a share of $11 \%$ from African countries (Gebeyehu, 2014). This paper draws on the leather products manufacturing industry (LPMI) in Ethiopia. Presently, the Ethiopian LPMI is at the forefront for the development of the leather sector in Africa in line with the current comparative advantage for the raw material needs of the industry (the first in Africa and tenth in the world in livestock population) (UNIDO, 2010). This industry is the leading exporter of manufactured products in Ethiopia, accounting $67 \%$ of the total export value generating from the manufacturing sector (Abdurehaman, 2012). However, its contribution to the national economy so far is lesser compared to its resource potentials (Gebeyehu, 2014). Apart from dozens 
of issues, high rates of turnover and low labor productivity are mentioned as seriously constraining factors for the development of the industry (Altenburg 2010; Addis et al., 2017a). Also, quality related issues in the LPMI of Ethiopia are mainly attributed to extensive human resource problems (Gebeyehu, 2014). It implies the need of strategic intervention that maneuvers the creation of productive employment in the industry. Scholars have argued that the most reliable predictor of turnover, low performance and low labor productivity is JS (Linley et al., 2009; Alsughayir, 2014). As Jung (2017) notes, JS is a single summary construct to capture employees' perceptions of how they are treated by their organization. Studying JS in relation to QM will provide a valuable comprehension for managers in the efforts to gain a sustainable workplace performance through HR perspectives and brings organizational wide change. Most of all, the findings will provide important empirical insights into the ongoing debates over the linkage between QM and HRM (Jimenez and Martinez, 2009).

The motive of the study to address shop-floor workers, who are directly involved in the production operations. Shop-floor workers are considered as the major cost-generating factors in most manufacturing organizations in terms of product quality and delivery (Ooi et al., 2008). Ooi et al. (2008) further argued that organizational performance is directly dependent on the effectiveness of shop floor workers. Moreover, scholars mentioned that quality management implementation heavily relies on the brawn and brain of front-line workers who are directly involved in making products (Karia and Asaari, 2006). However, authors in the quality management area rarely mention shop floor satisfaction in particular, while it likely affects different aspects of employees at workplaces (Ooi et al., 2008). Welikala and Sohal (2008) reported that "workers at the shop-floor level see quality management programs as coercive, due to increased pressure on them to continuously improve quality". Properly managing the quality management philosophy towards achieving higher satisfaction of shop floor workers is undoubtedly to the advantage of any organization. The distribution of employees' in the LPMI of Ethiopia showed that the vast majority of workers $(85-90 \%)$ are engaged directly in the production activities (Gebeyehu, 2014). Therefore, addressing shop floor workers is highly relevant for the improvement of operational and organizational performances of the industry.

\section{Methodology \\ 5.1 The sample}

The LPMI of Ethiopia is the focus of the present study. For the survey, companies were selected from Addis Ababa, capital of Ethiopia, where $98 \%$ of the total number of leather processing companies in the country are concentrated (Gebeyehu, 2014). As described above, the target respondents for this study were full-time production or shop floor workers. A total of 190 useable responses were collected representing $65 \%$ response rate, which is adequate considering the norm for response rate of $60+/-20$ for conventional population as suggested by Baruch (1999). A random sampling approach was used to draw the samples.

\subsection{The research instrument}

Data triangulation method was used through a combination of quantitative and qualitative methods. The reason for choosing the triangulation method is to get a rich and factual picture of the studied phenomenon (Lagrosen et al., 2010). For the quantitative part, a structured survey questionnaire was prepared that contains two major sections. The first section assesses the QM practices (i.e. TMLC, EP and CI) and the second section contains measurement items representing the general JS of employees.

The survey instrument developed by Cua et al. (2001), Conca et al. (2004) and Das et al. (2008) was used to verify the relationship between the practices of QM and JS. The instrument measures the adoption of TMLC using four items, five items for EP and four items for CI. For instance, the practice of TMLC contain the following items: 'Managers are committed to review quality issues comprehensively', 'Managers are a good example regarding quality activities', 'Managers are committed to recognize employees for superior quality performance' and 'There is a visible commitment from managers to understand a working situation within the organization'. The second section of the questionnaire was about the JS. The JS was queried with respect to three general JS (GJS) variables reflecting overall satisfaction of employees with their job. The items used to rate GJS were 'I feel personal satisfaction with the work of my job (JS 1$)$ ', 'My job fulfils my necessary needs $\left(\mathrm{JS}_{2}\right)$ ' and 'This is the best organization for me to work for $\left(\mathrm{JS}_{3}\right)$ ' (Jun and Shin, 2006; Abdulla et al., 2011; Ooi et al., 2013; Mendes and Jesus, 2016). These unidimensional general items are believed to contain both affective and cognitive components of satisfaction at work places (Mendes and Jesus 2016). The instrument used a five-point scale to indicate level of agreements ranging from (1) strongly dissatisfied /disagreed to (5) strongly satisfied/agreed, depending on the nature of a question. The data was obtained by the use of a self-rated questionnaire from shop floor workers and hence, the questionnaire is believed to provide a reasonable perception of the JS status (Karasek and Theorell, 1990).

The survey instrument was primarily translated into the local language of Ethiopia (i.e. Amharic) to avoid comprehension gaps. The authors translated the questionnaire and then two language experts, who are fluent in both languages, were consulted to ensure contextual equivalency. Also, the questionnaire was validated through 
a pilot survey using twenty people from two of the sample companies. The participant was asked to evaluate the question items for their readability, understandability and relevance to the Ethiopian manufacturing industry setting. The feedback resulted in the modification of some of the items in the instrument (Saunders et al., 2007).

For the qualitative part, three focus groups were organized with five workers in each group. Focus-group interview helps to obtain a deeper understanding of workers' perceptions of their working life and generate an extended useful data. A general question was asked to each group about the three QM practices during the interview. For example, TMLC was stated as: 'Describe how managers are working concerning quality in your company?' Follow-up questions were also asked about QM activities, their effects on JS of employees and regarding what is important for creating JS in the workplace. The qualitative data was analyzed using grounded theory approach, particularly the constant-comparison technique (Glaser and Strauss, 1967). This approach believes that theory and concepts could emerge through qualitative data analysis. It has proved its value in QM as well as in JS researches (e.g. Lagrosen et al., 2010; Staelens et al., 2016).

\section{Findings}

The Pearson correlation has been calculated to evaluate the degree of relationship between the QM practices and the JS index. Table 1 present the correlation results. It can be seen that all the QM practices have significant correlations with the JS Index. The size of the correlations can be considered high enough for such kind of study (Lagrosen et al., 2010). The findings are in agreement with previous researches (e.g. Prajogo and Cooper, 2010), which reported that perception of employees on QM practices and JS are closely related.

In the following, mechanics of the relationship between QM and JS is examined, i.e. TMLC, PE and CI were elaborated to identify which of its dimensions give rise to the effect of promoting JS in the LPMI of Ethiopia. For this purpose, the dimensions were extracted from the focus-group interviews. For the TMLC, four dimensions were extracted. These are given as under:

- Manage through visibility

- Compensations

- Bottom-up communication and

- Continuity

For the practice of EP, three dimensions were extracted. These are given as under:

- $\quad$ Keep employees informed

- Belongingness and

- Influence

Similarly, three dimensions were extracted under CI. These are:

- Appraisals \& development

- Trial ability \& innovation

- Thrust.

All the dimensions are presented in models to show their interrelationship (see Figure 1- Figure 3). The descriptions of each of the dimensions are provided below.

\subsection{The dimensions of 'TMLC'}

\subsubsection{Manage through visibility}

The manager's accessibility and their leadership were considered in this dimension. It was evident from the interviews that shop-floor level employees' have low work morale for variety of reasons. For instance, they said that 'managers don't practice what they preach'. It is revealed that if managers lead and teach by example, then employees' will put an effort to share the same and develop a sense of loyalty for improvements. In this regard, being a role model, leading by example and manager's integration with employees were considered as vital ingredients of the dimension.

6.1.2 Compensations

Incentive issues in the organizations are considered negative. One leather cutting machine operator said that 'there is less culture of praising efforts and achievements'. It was perceived that developing a formal compensation system is important to encourage individuals for quality enhancement. Managers need to make clear their expectations from a job and make employees' aware about the penalty and reward system. In this regard, devising a clear incentive or encouragement plan was considered vital.

\subsubsection{Bottom-up communication}

This dimension considered communication from employees to managers. Shop floor employees said that 'we are only engaged in executing managerial orders; ideas from our side are not emphasized'. It seems organizations are characterized by a working culture of 'top-down hierarchical structure', which make employees' to solely rely on top managers' orders and decisions. It is perceived to be important if employees are able to communicate with personnel at the managerial level. Managers must provide distinct channel to communicate with employees' 
and be alert to listen their voice with relation to quality improvements.

6.1.4 Continuity

Management and supervisory turnover were perceived as influencing job-related attitude of employees'. For instance, employees said that 'what is said about compensation establishments are eventually forgotten or neglected when managers are changed'. In addition, it was revealed that managers are motivating employees' only for the execution of short-term objectives (e.g. short-term profits), while QM requires organizational changes through a long-term paradigm shift.

A model for the dimensions of TMLC is shown in Figure 1. The model explains the requirement of managers to integrate them with employees', encourage employees through compensations and listen voice of employees. Also, the model depicts that frequent mobility of managers should be alleviated to sustain a longterm paradigm shift in organizations.

\subsection{The dimensions of 'EP'}

\subsubsection{Keep employees informed}

The extent of communication of managers to employees' is considered under this dimension. The information forwarded from managers about their work priorities, successes of quality initiatives, etc. were considered as an important part of the dimension. It was reported that managers are not alert to notify employees about important organizational issues. One of the shop floor workers said that 'managers notice us only when something goes wrong while keeping delightful moments like goal achievements with them'.

\subsubsection{Belongingness}

The less complexity of the organizations under study provides an opportunity of involving employees' in organizational issues. However, it was revealed that organizations are not focused to sustain employee involvement. Particularly, it was understandable that the level of participation of shop floor workers in organizational issues is at infant stage. Their attitude was expressed as 'I do my shift work and that is it'.

\subsubsection{Influence}

This dimension deals with empowerment of employees to make decisions and solve problems. The logic behind this dimension is that the people closest to a problem are in the best position to make decisions for improvement. For the conditions to be perceived as being fair, it is required to delegate responsibilities to employees for their level and able to give advice for others who are facing similar problems that they experience. According to the shop floor workers, work-related decisions entirely lies with managers. In addition, lack of entrusting employees with resources were reported as affecting their contribution towards the effective running of the company's operation.

A model for the dimensions of EP is shown in Figure 2. The model explains that when employees are kept informed about organizational issues, they develop a sense of ownership and then enact changes in their organizations.

\subsection{The dimensions of ' $\mathrm{CI}$ '}

\subsubsection{Appraisals and development}

Organizations did not seem to recognize employees' as being the life-blood of the company. Appraisals and promotion from 'within' was not revealed as the preferred approach in the organizations, as every new position is being advertised externally. One said that 'there is less/no opportunity for the development of workers in the shop-floor level'. For the conditions in the company to be perceived as fair, employees should be provided with the possibilities of performance appraisals and development.

\subsubsection{Trial ability and innovation}

It was revealed that encouragement and promotion of innovative thinking is not an integral part of the working culture throughout the organizations. According to the respondents, shop floor workers are not encouraged and motivated to introduce new ideas and find solutions, even for simple manufacturing problems within their responsibility. One of the worker said 'we keep doing the task assigned only and the rest is for technical managers'. There is less belief in organizations that innovations can only flourish in an environment that encourages to foster it.

6.3.3 Thrust

This dimension considers an issue that demoralize employees' not to put in their full effort in their work. Employees' reported that they have less freedom in their job and there is only completed responsibility for their results. This sometimes creates annoying situations. Effective management of people requires a high level of trust, because a fearful environment cannot make employees' to be committed towards their job. Although organizations claim that employees were empowered, some of the shop floor employees complained that the actual work environment do not provide a trustful environment.

A model for the dimensions of CI is shown in Figure 3. The model depicts that employees require developments in work capabilities, which helps to improve creative thinking and innovativeness. 


\section{Implications for the role of JS in QM theory}

In the previous section, QM dimensions were extracted and discussed that are important to realize JS. To further explicate the role of QM in rising JS status, each of the dimensions were compared and crosschecked with concepts found in the QM literature.

\subsection{The dimensions of ' $T M L C$ '}

\subsubsection{Manage through visibility}

Ahmad and Yusof (2010) views that top management should sustain their commitment to quality improvement initiatives by taking an active role in all quality management activities. Managers need to create and sustain clear and visible quality values that guides company towards excellence. According to Lagrosen et al. (2010), visible involvement of managers in leading total quality and sustain a consistent total quality culture are amongst the major aspects of TMC. Visibility of managers' commitment require devoting a substantial portion of time to quality-related matters (Thiagaragan et al., 2001). This may include learning quality-related concepts and skills, teaching employees', attending training courses with employees', regular meetings with employees', arranging adequate resources for quality efforts, using quality tools in daily work, giving recognitions and celebrating successes. This concept also involves displaying data at workstations (Seetharaman et al., 2006). Several diverse organizations have underscored the critical role of TMC in providing visible leadership; for instance, Dunlop Ltd in Malaysia; Xerox Inc. in USA; Asahi Breweries Ltd in Japan (Ahire et al., 1996).

\subsubsection{Compensations}

Scholars argued that QM initiative in organizations must be supported with a formal compensation system in order to encourage and motivate employees to achieve the desired performance (Talib et al., 2015). Compensation often consist of financial (e.g. salary promotions and bonuses) and non-financial rewards (e.g. recognitions) for members of an organization who contribute to QM efforts (Blackburn and Rosen, 1993). Organizations that are serious about achieving quality must integrate these aspects of QM into their incentive plans (Zhang, 1997). The effective implementation of employee compensation system support organizations to create a strong link between quality and customer satisfaction.

\subsubsection{Bottom-up communication}

Communication is considered as a cement that holds the bricks of total quality process together to support the principle of people-based management (Wali et al., 2003). According to Ahmad and Yusof (2010), managers in QM environment are required to listen to what employees' truly need and listen their concerns, views and suggestions, considering it as a starting-point of improvement planning process. Bottom-up communication channels help employees' to easily voice their concerns and enable them to participate in decision-making processes (Prajogo and Cooper, 2010). This may involve face-to-face meetings (Daily and Bishop, 2003), suggestion schemes (Baidoun and Zairi, 2003) and using feedback from employee surveys (Thiagaragan et al., 2001). Not only that, empathetic listening has also been indicated as an important feature in QM environment to facilitate a positive work-related attitude (Lagrosen et al., 2010).

\subsubsection{Continuity}

Management turnover is one of the obstacles for successful implementation of QM (Mohammad, 2014). Deming (1986) said that mobility of management is amongst the deadly diseases affecting organizations in the Western world. Scholars often reported that high turnover of management level is hindrance for the successful implementation of quality programs in different organizations (Talib et al., 2015). In their survey-based study, Lagrosen et al. (2010) reported that promises like personnel development are forgotten when new manager joins organizations. Frequent changes of managers may ruin trust in organizations, which may take time to rebuild. QM demands persistence throughout the organization in accordance with a clear and widely understood vision (Zhang, 1997). One of the 14 principles of Deming (i.e. constancy of purpose) also requires organizations to emphasize long-term views like consistent improvement of products/services. This requires publishing a resolution in employees' that makes them keep contributing to quality. Talavera (2005) said that the quest for quality should be continuing.

\subsection{The dimensions of ' $E P$ '}

\subsubsection{Keep employees informed}

According to Thiagaragan et al. (2001), keeping employees informed (about organizational objectives, the progress being made, developments, achievements made by individuals etc.) determine the enhancement of quality efforts. Scholars emphasized that QM success appears to depend critically on an ambience of open dialog about quality progress (Powell, 1995; Jha and Kumar, 2012). For instance, in order to enhance the commitment to quality, managers must convey their priorities and expectations to their employees' (Demirbag and Sahadev, 2008). Also, scholars indicate that difficulties in quality efforts may arise from information filtering. According to Zakuan et al. (2012), when visions of quality set by top management filters down through the ranks, it will lose its clarity and momentum. Communication gaps can be widening steadily and may result in unbridgeable 
gulf of total misunderstanding within organizations (Drucker, 1974). Employees' need to be informed about quality initiatives, which in turn is directly related to their satisfaction at workplaces (Baidoun and Zairi, 2003).

7.2.2 Belongingness

Belongingness is described as the perception of being involved with others at differing interpersonal levels which contributes to one's sense of connectedness (being part of and feeling accepted) and esteem (being valued and respected by others) (Somers, 1999). Employee involvement is believed to promote job characteristics positively, such as prestige and self-respect (self-esteem) (Liu and Liu, 2014). In the QM program, employee involvement aims to create a sense of belonging, which in turn enhance employees' ownership in their jobs (Welikala and Sohal, 2008). As Liu and Liu (2014) reported, people who feel belongingness are more likely experience happiness and general well-being.

7.2.3 Influence

Participation of employees' in decision-making and power delegation to control process improvements, implement ideas and solve problems results in empowered employees' (Welikala and Sohal, 2008). Selfmanagement is one of the tools of empowerment that involves employees' being given responsibility and accountability about their job (Dimitriades, 2002). Self-management assumes that once all employees are empowered to meet the inherent challenges in a quality environment, they will put their effort for extra role performances. Ladrgson et al. (2010) reported that, 'It is important that all employees' feel they can demonstrate initiative and that they have the responsibility to enact changes and influence activities in their own area of work'. Therefore, it is vital to empower employees to make them active participant in a quality environment, which is in fact intrinsically at the heart of the QM concept (Sun et al., 2000).

\subsection{The dimensions of ' $C I$ '}

\subsubsection{Appraisals and development}

In the QM environment, everyone is required to gain additional capabilities to work with continuous improvements (Welikala and Sohal, 2008). QM-oriented organizations mainly use performance appraisal for training and developmental opportunities (Soltani, 2003). A case study carried out by Cowling and Newman (1995) reported that QM-oriented appraisal systems offer personal development, which then improves JS. QMoriented appraisals need to focus on how the performance of employees' is evaluated for their selection to development (Evan and Lindsay, 2002).

\subsubsection{Trial ability and innovation}

According to Gouthier and Rhein (2011), innovation is the most important element of QM that characterize CI. It deals about searching for never-ending improvements and developing processes to find new or improved methods of making useful outputs. Encouraging trial ability and creativity are mentioned as amongst the basic elements of QM (Guimaraes, 1996; Mosadeghrad, 2015). Trial ability is the degree to which an innovation can be experimented (Sinha et al., 2016). Through experimentation, employees' can try out novel ways of handling problems in their organization. Scholars reported that employees' need to be creative to propose innovative ideas and solutions for challenges occurred in their level of responsibility (Gouthier and Rhein, 2011). Naser et al. (2001) said that CI in QM can be achieved by elevating the performance of an employee, not by blaming employees' and offering threat of punishment. Off course, Trial-and-error learning is the hallmark of TQM (Dooley, 2000). One of the 14 principles of Deming also focus on 'Drive out fear'. This helps employees' work more effectively. With openness, employees' can share their ideas without the fear of being ridiculed and are not defensive about it (Sinha et al., 2016).

7.3.3 Thrust

Trust refers to the extent to which the organization beliefs their employees' capabilities and abilities to have control over their work (Boon et al., 2007). In QM effort, leadership, particularly charismatic leaders, are expected to project self-confidence and infuse their followers with positive values so that they may perceive meaning in their work (Shamir et al., 1993). According to Mohammad (2014), an organization oriented towards QM should develop a "corporate culture of quality" that aimed to promote high-trust relationships and motivation. This climate of openness and trust favors creativity and participation of employees' (Bou and Beltrán, 2005). According to Baidoun and Zairi (2003), CI requires bottom-up Trust to promote commitment of employees'.

In summary, it is revealed that all of the satisfaction dimensions are founded in the main corpus of the QM literature. It provides empirical evidence for the importance of adopting QM for the improvement of JS and thus implementing QM does payoff (Boon et al., 2006). The findings also strengthen the theoretical assumptions that QM is not only for enhancing quality but also for improving the JS status of employees'.

\section{Conclusions}

The main objective of the study was to examine the mechanics of the relationships between JS and the QM practices (TMLC, EP and CI). The underlying dimensions were extracted from the QM practices that are 
believed to realize JS. The underline dimensions discovered under the TMLC were 'manage through visibility', 'compensation', 'bottom-up communication' and 'continuity'. The dimensions for EP are found to be 'keep employees informed', 'belongingness' and 'influence'. The underline dimensions for CI are 'appraisals and development', 'trial ability and innovation' and 'thrust'. These dimensions have been cross-checked with the fundamental ideas in the QM theory and shown to be constituted in it. It augments the existing unclear understanding of the connection between QM and JS. Through the increased knowledge from this study, managers can improve the JS of employees and maximize organizational gains via human resource perspectives. For OM researchers, the finding provides a testing ground in which to explore the ongoing debate on the connection between HRM and QM.

\section{References}

Abdulla, J., Djebarni, R. \& Mellahi, K. (2011) 'Determinants of job satisfaction in the UAE: A case study of the Dubai police', Personnel review, 40(1), 126-146.

Abdurrahman, A. (2012) 'The Dynamics of Internationalization of Ethiopian Leather Industry Development Institute (ELIDI)', MA thesis, Addis Ababa University, Ethiopia.

Addis, S., Dvivedi, A. \& Beshah, B. (2017a) 'Identifying and prioritising operational performance indicators of the Ethiopian leather industry', Int. J. Productivity and Quality Management, 22(3), 378-394.

Addis, S., Dvivedi A. \& Abebe B. (2017b), 'Decision-making on job satisfaction improvement programmes using fuzzy QFD model: a case study in Ethiopia', Total Quality Management \& Business Excellence, 1-24. http://dx.doi.org/10.1080/14783363.2017.1354693

Addis, S., Dvivedi, A. \& Beshah, B. (2018) 'Determinants of job satisfaction in Ethiopia: Evidence from shopfloor workers in the leather industry', African Journal of Economic and Management Studies, 9(4), 410-429. http://doi.org/10.1108/AJEMS-09-2017-0222.

Addis, S., Dvivedi, A. \& Beshah, B. (2019) 'Quality management practices as a tool for job satisfaction improvement of shop-floor workers: Empirical evidence from the Ethiopian manufacturing organizations', Production Planning \& Control, https://doi.org/10.1080/09537287.2019.1574510.

Ahire, S. L., Golhar, D. Y. \& Waller, M. A. (1996) 'Development and validation of TQM implementation constructs', Decision sciences, 27(1), 23-56.

Ahmad, M. F. B. \& Yusof, S. R. M. (2010) 'Comparative study of TQM practices between Japanese and nonJapanese electrical and electronics companies in Malaysia: Survey results', Total Quality Management, 21(1), 11-20.

Alsughayir, A. (2014) 'Does practicing total quality management affect employee job satisfaction in Saudi Arabian organizations', European Journal of Business and Management, 6(3), 169-175.

Altenburg, T. (2010) 'Industrial policy in Ethiopia', German Development Institute, Bonn, Germany.

Baidoun, S. \& Zairi, M. (2003) 'A proposed model of TQM implementation in the Palestinian context', Total Quality Management \& Business Excellence, 14(10), 1193-1211.

Baruch, Y. (1999) 'Response rate in academic studies-A comparative analysis', Human Relations, 52(4), 421438.

Blackburn, R. \& Rosen, B. (1993) 'Total quality and human resources management: lessons learned from Baldrige award-winning companies', Academy of Management Executive, 7(3), 49-66.

Boon, O. K., Veeri, A., Kim Y. L. and Subathra V. L. (2006) 'Relationships of TQM practices and employees' propensity to remain: An empirical case study', The TQM Magazine, 18(5), 528-541.

Bou, J. C. \& Beltrán, I. (2005) 'Total quality management, high-commitment human resource strategy and firm performance: An empirical study’, Total Quality Management \& Business Excellence, 16(1), 71-86.

Boudreau, J., Hopp, J.O., \& McClain, L.J. (2003) 'On the interface between operations and human resources management', Manufacturing and Service Operations Management, 5 (3), 179- 02.

Conca, F. J., Llopis J. \& Tarí, J. J. (2004) 'Development of a measure to assess quality management in certified firms', European Journal of Operations Research, 156(3), 683-697.

Cowling, A. \& Newman, K. (1995) 'Banking on people: TQM, service quality, and human resources', Personnel Review, 24(7), 25-40.

Cua K. O., McKone K. E. \& Schroeder R. G. (2001) 'Relationships between implementation of TQM, JIT, and TPM and manufacturing performance', Journal of Operations Management, 19(6), 675-694.

D Menezes L. M. (2012) 'Job satisfaction and quality management: an empirical analysis', International journal of Operations \& Production Management, 32(3), 308-328.

Dahlgaard, J., Kristensen, K. \& Kanji, G. K. (2002) 'Fundamentals of Total Quality Management: Process Analysis and Improvement', Taylor \& Francis Group, London.

Daily, B. F. \& Bishop J. W. (2003) 'TQM workforce factors and employee involvement: the pivotal role of teamwork', Journal of Management Issues, 15(4), 393-412.

Das, A., Paul, H. \& Swierczek, F. W. (2008) 'Developing and validating total quality management (TQM) 
constructs in the context of Thailand's manufacturing industry', Benchmarking: An International Journal, 15(1), 52-72.

Dean, J. W. and Bowen, D. E. (1994) 'Management theory and total quality: improving research and practice through theory development', Academy of management review, 19(3), 392-418.

Demirbag, M. and Sahadev, S. (2008) 'Exploring the antecedents of quality commitment among employees: an empirical study', International Journal of Quality and Reliability Management, 25(5), 494-507.

Deming, W. E. (1986) 'Out of Crisis', Cambridge, Massachusetts Institute of Technology, USA.

Del Río-Rama, M. D., Álvarez-García, J., Saraiva, M., \& Ramos-Pires, A. (2016) 'Influence of quality on employee results: the case of rural accommodations in Spain', Total Quality Management \& Business Excellence, 1-20. DOI: 10.1080/14783363.2016.1150171.

Dimitriades, Z. S. (2002) 'Empowerment in total quality: designing and implementing effective employee decision-making strategies', Measuring Business Excellence, 6(2), 67.

Dooley, K. (2000), 'The paradigms of quality: evolution and revolution in the history of the discipline', Advances in the management of organizational quality, 5(1), 1-28.

Drucker, P. (1974) 'Management: Tasks, Responsibilities, Practices', New York: HarperCollins

Ellickson, M.C., \& Logsdon, K. (2002) 'Determinants of job satisfaction of municipal government employees', Public Pers Manag, 31(3), 343-358.

Evans, J. R, \& Lindsay, W. M (1999) 'The management and control of Quality', New York, West Publishing.

Evan, J. R., \& Lindsay, W. M. (2002) 'Performance Measurement and Strategic Information Management, Human Resources Practices, The Management and Control of Quality', Ohio: South-Western.

Flynn, B. B., Schroeder, R. G. \& Sakakibara, S. (1995) 'The impact of quality management practices on performance and competitive advantage', Decision Sciences, 26(5), 659-691.

Gebeyehu, S. G. (2014) 'Developing Sector Specific VET for the Ethiopian Leather Product Manufacturing Sector (Work-Process Oriented Approach)', PhD thesis, Bergische University of Wupperta, Germany.

Glaser, B. G., and Strauss, A. L. (1967) 'The discovery of grounded theory: Strategies for qualitative research', Hawthorne, NY: Aldine.

Gouthier, M. H., \& Rhein, M. (2011) 'Organizational pride and its positive effects on employee behavior', Journal of Service Management, 22(5), 633-649.

Guimaraes, T. (1996) 'TQM's impact on employee attitude', The Total Quality Management, 8(5), 20-5

Jha, U. C. \& Kumar, S. (2012) 'Effect of TQM on employee satisfaction', Journal of Radix International Educational and Research Consortium, 1(8), 1-15.

Jimenez-Jimenez, D. \& Martinez-Costa, M. (2009) 'The performance effect of HRM and TQM: a study in Spanish organizations', International Journal of Operations \& Production Management, 29(12), 1266-1289.

Jun, M., Cai, S. \& Shin, H. (2006) 'TQM practice in maquiladora: Antecedents of employee satisfaction and loyalty', Journal of Operation Management, 24(6), 791-812.

Jung, C. S. (2017) 'Current-Ideal Culture Incongruence, Hierarchical Position, and Job Satisfaction in Government Agencies', International Public Management Journal (forthcoming). doi: 10.1080/10967494.2016.1276492

Kabak, K. E., Şen, A., Göçer, K., Küçüksöylemez, S. \& Tuncer, G. (2014) 'Strategies for Employee Job Satisfaction: A Case of Service Sector', Procedia-Social and Behavioral Science, 150: pp. 1167-1176. doi: 10.1016/j.sbspro.2014.09.132

Karasek, R. \& Theorell, T. (1990) 'Healthy Work, Stress, Productivity, and the Reconstruction of Working Life', Basic Books, New York.

Karia, N. \& Asaari, M. H. (2006) 'The effects of total quality management practices on employees' work-related attitudes', The Total Quality Management, 18(1), 30-43.

Lagrosen, Y., Backstrom, I. \& Lagrosen, S. (2010) 'The relationship between quality management and healthexploring the underlying dimensions', International Journal of Productivity and Quality Management, 5(2), 109-123.

Lam, S. S. (1995) 'Quality management and job satisfaction: an empirical study', International Journal of Quality \& Reliability Management, 12(4), 72-78.

Linley, P. A., Maltby, J., Wood, A.M., Osborne, G. \& Hurling, R. (2009) 'Measuring happiness: The higher order factor structure of subjective and psychological well-being measures', Personality and Individual Differences, 47(8), 878-884.

Liu, N. C. \& Liu, W. C. (2014) 'The effects of quality management practices on employees' well-being', Total Quality Management \& Business Excellence, 25(11-12), 1247-1261.

Martin J. \& Adair, D. (2016) 'Perception of TQM benefits, practices and obstacles', The TQM Journal, 28(2), $317-336$.

Mendes, L. \& Jesus, J. (2016) 'Influence of total quality-based human issues on organizational commitment', Total Quality Management \& Business Excellence, 1-27. doi: 10.1080/14783363.2016.1180953 
Mohammad, M. A. (2014) 'Why TQM programmes fail? A pathology approach', The TQM Journal, 26(2), 160187.

Mosadeghrad, A. M. (2015) 'Developing and validating a total quality management model for healthcare organizations', The TQM Journal, 27(5), 544-564.

Naser, A. M., Anuar, M. K. \& Idris, F. (2011) 'The influence of total quality management (TQM) on operational flexibility in Jordanian hospitals: Medical workers' perspectives', Asian Journal on Quality, 12(2), $204-222$.

Neumann, W.P., \& Dul J., (2010) 'Human Factors: Spanning the Gap between OM \& HRM (No. ERS-2010020-LIS)', ERIM report series research in management Erasmus Research Institute of Management. Erasmus Res Institute of Management. http://hdl.handle.net/1765/19668. (Accessed 26 January 2017).

Ooi K. B., Arumugam V., Teh P. L. \& Yee-Loong C. (2008) 'TQM practices and its association with production workers', Industrial Management \& Data Systems, 108 (7), 909-927.

Ooi, K. B., Lee, V. H., Chong, A. \& Lin, B. (2013) 'Does TQM improve employees' quality of work life? Empirical evidence from Malaysia's manufacturing firms', Production Plan \& Control, 24(1), 72-89.

Powell, T. C. (1995) 'Total quality management as competitive advantage: a review and empirical study', Strategic management journal, 16(1), 15-37.

Prajogo, D. I., and Cooper, B. K. (2010) 'The effect of people-related TQM practices on job satisfaction: a hierarchical model', Production Planning and Control, 21(1), 26-35.

Psomas, E. L. \& Fotopoulos, C.V. (2009) 'A meta-analysis of ISO 9001:2000 research - findings and future research proposals', International Journal of Quality and Service Sciences, 1(2), 128-144.

Rahman, S. \& Bullock, P. (2005) 'Soft TQM, hard TQM, and organizational performance relationships: an empirical investigation', Omega, 33(1), 73-83.

Saraph, J. V., Benson, P. G. \& Schroeder, R. G. (1989) 'An instrument for measuring the critical factors of quality management', Decision Sciences, 20(4), 810-29.

Sarathy, P. S. (2013) 'TQM practice in real-estate industry using AHP', Quality \& Quantity, 47(4), 2049-2063.

Saunders, M., Lewis, P. and Thornhill, A. (2007) 'Research Methods in Business Studies', Prentice-Hall, Harlow.

Schroeder, R.G., Linderman, K., \& Zhang, D. (2005) 'Evolution of quality: first fifty issues of production and operations management', Production and Operation Management, 14(4), 468-481.

Seetharaman, A., Sreenivasan, J. \& Boon, L. P. (2006) 'Critical success factors of total quality management', Quality and quantity, 40(5), 675-695.

Shamir, B., House, R. J. \& Arthur, M. B. (1993) 'The motivational aspects of charismatic leadership: a selfconcept theory', Organizational Science, 4(4), 1-17.

Sila, I. \& Ebrahimpour, M. (2005) 'Critical linkages among TQM factors and business results', International Journal of Operations and Product Management, 25(11), 1123-55.

Sinha, N., Garg, A. K., Dhingra, S. \& Dhall, N. (2016) 'Mapping the linkage between Organizational Culture and TQM: The case of Indian auto component industry', Benchmarking: An International Journal, 23(1), 208-235.

Soltani, E., Van der Meer, R., Gennard, J. \& Williams, T. M. (2003) 'A TQM approach to HR performance evaluation criteria', European Management Journal, 21(3), 323-37.

Somers, M. (1999) 'Development and preliminary validation of a measure of belongingness (PhD, psychology thesis)', Temple University, Philadelphia, USA.

Staelens, L., Desiere, S., Louche, C. \& D'Haese, M. (2016) 'Predicting job satisfaction and workers' intentions to leave at the bottom of the high value agricultural chain: evidence from the Ethiopian cut flower industry', The International Journal of Human Resource Management, 29, 1-27, doi:10.1080/09585192.2016.1253032.

Sun, H., Kee Hui, I., Tam, A. Y. \& Frick, J. (2000) 'Employee involvement and quality management', The TQM Magazine, 12(5), 350-354.

Talavera, M. (2005) 'TQM adoption and firm performance in the Philippines', Philippine Management Review, 12(1), 23-44.

Talib, F. \& Rahman, Z. (2015) 'Identification and prioritization of barriers to total quality management implementation in service industry: an analytic hierarchy process approach', The TQM Journal, 27(5), 591615.

Talib, F. \& Rahman, Z. (2012) 'Total quality management practices in manufacturing and service industries: a comparative study', International Journal of Advanced Operations Management, 4(3), 155-176.

Thiagaragan, T., Zairi, M., \& Dale, B. G. (2001) 'A proposed model of TQM implementation based on an empirical study of Malaysian industry', International Journal of Quality \& Reliability Management, 18(3), 289-306.

UNIDO-United Nations Industrial Development Organization (2010) 'Future trends in the world leather and leather products industry and trade', Vienna.

Wali, A. A., Deshmukh, S. G. \& Gupta, A. D. (2003) 'Critical success factors of TQM: a select study of Indian organizations’, Production Planning \& Control, 14(1), 3-14. 
Welikala, A. D. \& Sohal, A. S. (2008) 'Total Quality Management and employees' involvement: A case study of an Australian organization', Total Quality Management, 19(6), 627-642.

Wilkinson, A. (1992) 'The other side of quality: 'soft' issues and the human resource dimension', Total Quality Management, 3(3), 323-330.

Wright P. M., McMahan G. C. and McWilliams A. (1994), "Human resources and sustained competitive advantage: a resource-based perspective", International journal of human resource management, 5(2), 301326.

Yee, R.W., Yeung, A.C., \& Cheng, T.E. (2008) 'The impact of employee satisfaction on quality and profitability in high-contact service industries', Journal of operations management, 26(5), 651-668.

Zakuan, N., Muniandy, S., Saman, M. Z. M., Ariff, M. S. M., Sulaiman, S. \& Jalil, R. A. (2012) 'Critical success factors of total quality management implementation in higher education institution: a review', International Journal of Academic Research in Business and Social Sciences, 2(12), 19.

Zhang, Z., (1997) 'Developing a TQM quality management method model'. University of Groningen, Groningen.

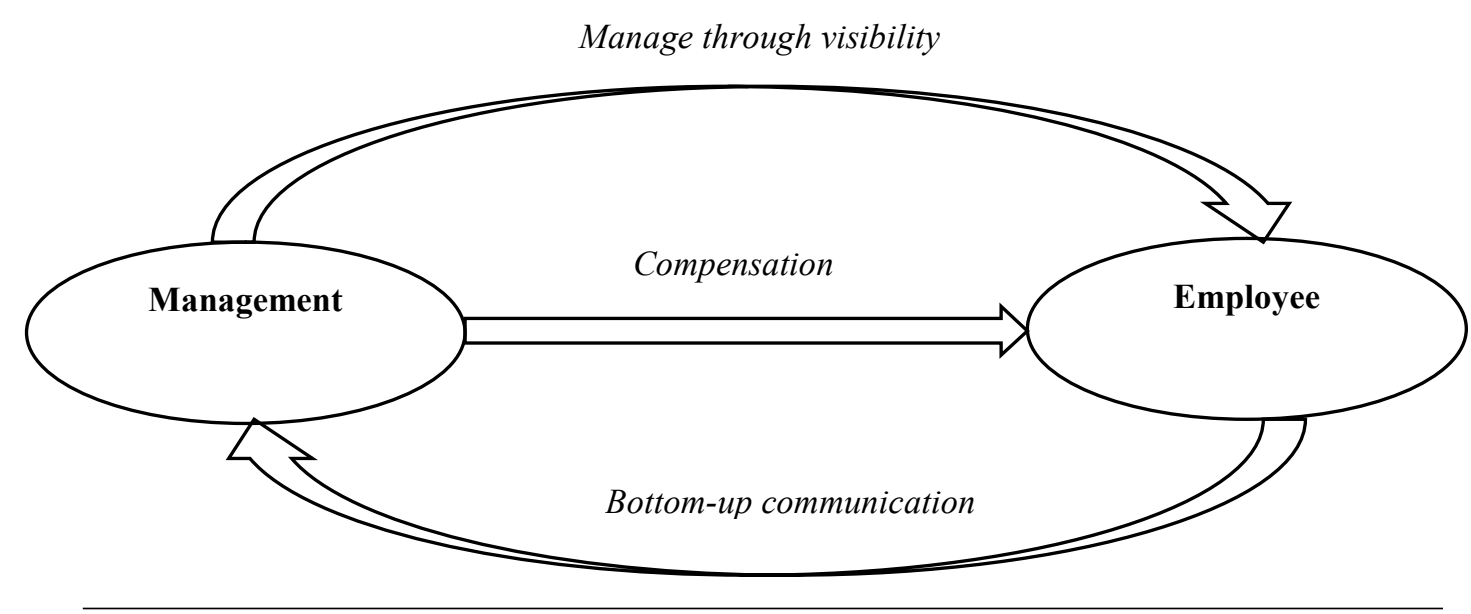

\section{Continuity}

Figure 1. A model for the dimensions of 'TMLC'

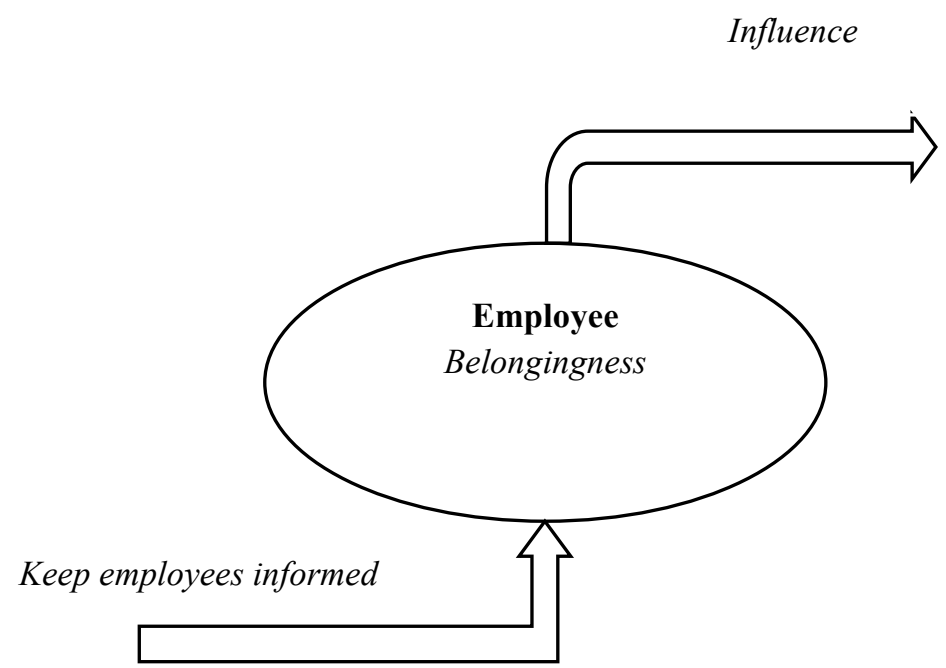

Figure 2. A model for the dimensions of 'EP' 
Innovation

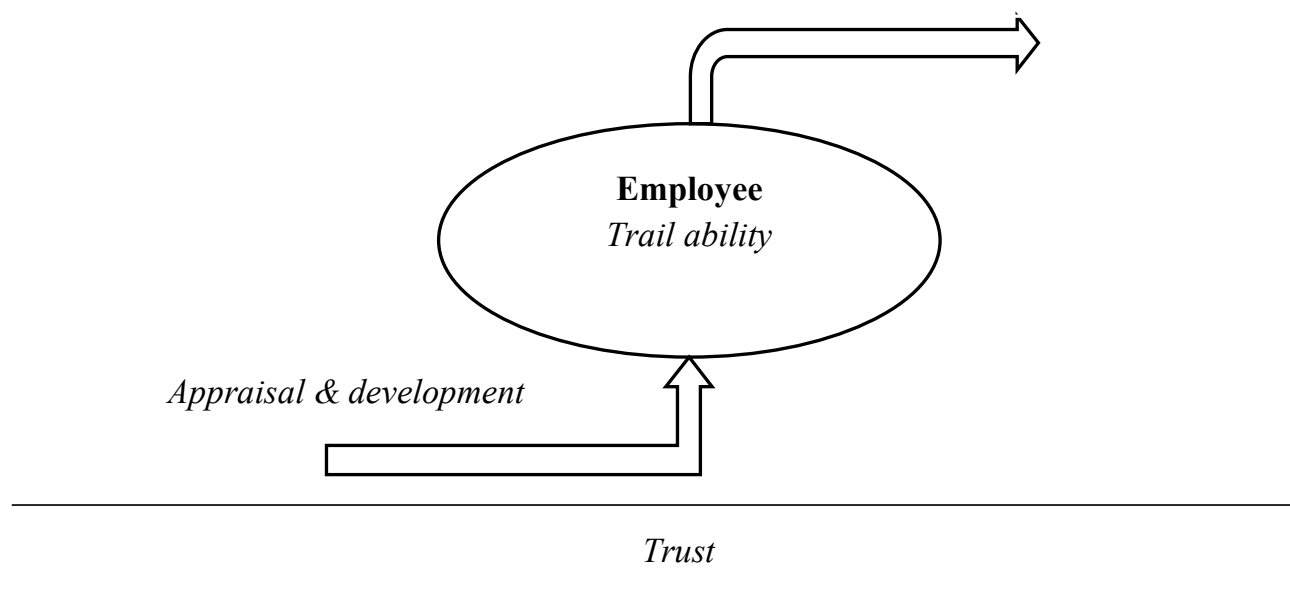

Figure 3. A model for the dimensions of 'CI'

Table 1. Correlations between the QM practices and the JS index.

\begin{tabular}{|l|c|c|c|}
\hline \multicolumn{1}{|c|}{ Practices } & Correlation & Sig. & Remark \\
\hline Top management leadership commitment (TMLC) & $0.602^{* *}$ & 0.000 & Significant \\
\hline Everybody's participation (EP) & $0.652^{* *}$ & 0.000 & Significant \\
\hline Continuous improvement (CI) & $0.354^{* *}$ & 0.000 & Significant \\
\hline
\end{tabular}

Note: Level of significance: $* * p<0.01$ 